\title{
molecules
}

ISSN 1420-3049

(C) 2007 by MDPI

http://www.mdpi.org/molecules

Full Paper

\section{Ultrasound Assisted Synthesis of 5,9-Dimethylpentadecane and 5,9-Dimethylhexadecane - the Sex Pheromones of Leucoptera coffeella}

Nhuan Ngoc Doan ${ }^{1, \S}$, Thach Ngoc Le ${ }^{2}$, Hao Cong Nguyen ${ }^{3}$, Poul Erik Hansen ${ }^{1}$ and Fritz Duus ${ }^{1, *}$

${ }^{1}$ Department of Science, Systems and Models, Roskilde University, P. O. Box 260, DK-4000 Roskilde, Denmark; E-mails: dnnhuan@hcmuns.edu.vn, poulerik@ruc.dk

2 Department of Organic Chemistry, University of Natural Sciences, National University of Ho Chi Minh City, 227 Nguyen Van Cu, Ho Chi Minh City, Vietnam; E-mail: lenthach@hcm.vnn.vn

${ }^{3}$ Institute of Natural Products Chemistry of Ho Chi Minh City, 01 Mac Dinh Chi, Ho Chi Minh City, Vietnam; E-mail: nguyenconghao@yahoo.com

$\S$ On leave from the University of Natural Sciences, National University of Ho Chi Minh City, Vietnam.

* Author to whom correspondence should be addressed; E-mail: fd@ruc.dk.

Received: 8 August 2007; in revised form: 23 August 2007 / Accepted: 23 August 2007 / Published: 28 August 2007

\begin{abstract}
Racemic 5,9-dimethylpentadecane and 5,9-dimethylhexadecane, the major and minor constituents, respectively, of the sex pheromone of Leucoptera coffeella, have been synthesized from citronellol in 56-58\% overall yield through six steps. Ultrasound irradiation efficiently supported tosylation of alcohols (two steps) as well as the subsequent cross coupling reactions with the pertinent Grignard reagents (also two steps).
\end{abstract}

Keywords: 5,9-Dimethylpentadecane; 5,9-Dimethylhexadecane; Ultrasound irradiation; Pheromones; Leucoptera coffeella. 


\section{Introduction}

Recent research has shown that several hydrocarbons with a 1,5-dimethyl skeleton are insect pheromones [1]. 5,9-Dimethylpentadecane (1) and 5,9-dimethylhexadecane (2) are known as the major and minor constituents, respectively, of the sex pheromone of Leucoptera coffeella, a pest of coffee trees [2]. Several ways of synthesizing $\mathbf{1}$ have been described. Stereoisomers of $\mathbf{1}$ were synthesized starting from (-)-isopulegol by Moreira and Correa [3] and from methyl (R)- and (S)-3-hydroxy-2methylpropanoate by Kuwahara and co-workers [4]. Zarbin et al. carried out an unsymmetrical double Wittig olefination as the key reaction to obtain also a stereoisomeric mixture of 1 in a yield of 54\% [5]. Using citronellol as the starting material, Liang et al. synthesized stereoisomeric mixtures of $\mathbf{1}$ as well as of 2 in yields of about 25\% [6]. Using (R)-citronellol as the starting material, Poppe et al. synthesized $\mathbf{1}$ as a mixture of the (5S,9S) and (5R,9S) stereoisomeric molecules in a related way in an overall yield of $22 \%$ [7]. However, the stereochemistry of the natural pheromone is still undetermined [5]. Zarbin et al. [5] have tested the biological activity of a synthetic stereoisomeric mixture of $\mathbf{1}$. Their field experiments showed, that it was highly attractive to L. coffeella males [5].

Ultrasonic irradiation has been found useful as support for quite a few organic reactions [8]. In this paper, we describe a new six-step synthetic route to $\mathbf{1}$ and $\mathbf{2}$ (as a mixture of stereoisomers) from citronellol (3) (see Scheme 1) in which ultrasound irradiation was used to support the tosylation and cross coupling reactions, which were used repeatedly (four out of six steps, see Scheme 1).

Scheme 1: Synthesis of 5,9-dimethylpentadecane (1) and 5,9-dimethylhexadecane (2).

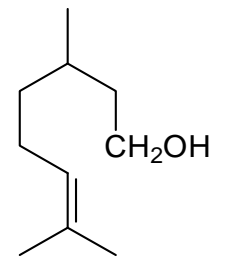

3

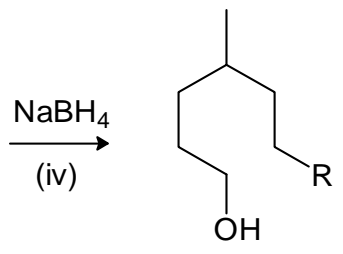

7a, 7b

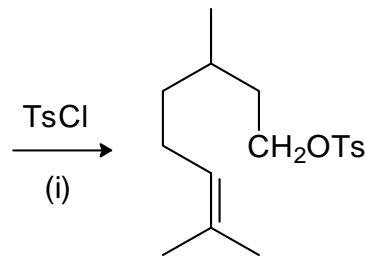

4

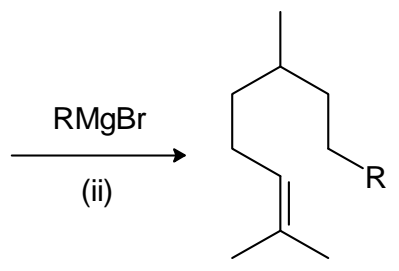

$5 a, 5 b$

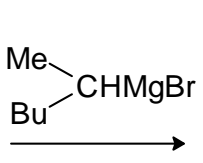

(vi)

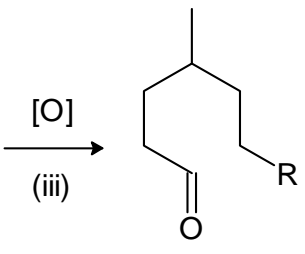

$6 a, 6 b$

a: $\mathrm{R}=n-\mathrm{C}_{4} \mathrm{H}_{9} ; \mathbf{b}: \mathrm{R}=n-\mathrm{C}_{5} \mathrm{H}_{11} ; \mathbf{1}: \mathrm{R}=n-\mathrm{C}_{4} \mathrm{H}_{9} ; 2: \mathrm{R}=n-\mathrm{C}_{5} \mathrm{H}_{11}$.

(i): Tosyl chloride, pyridine, $\mathrm{CHCl}_{3}$, ultrasound; (ii): $n-\mathrm{C}_{4} \mathrm{H}_{9} \mathrm{MgBr}$ or $n-\mathrm{C}_{5} \mathrm{H}_{11} \mathrm{MgBr}, \mathrm{Li}_{2} \mathrm{CuCl}_{4}$, THF, $-78{ }^{\circ} \mathrm{C}$, ultrasound; (iii): perphthalic acid, then $\mathrm{HIO}_{4}$, THF; (iv): $\mathrm{NaBH}_{4}, \mathrm{MeOH}$; (v): the same as (i); (vi): $\mathrm{BuMeCHMgBr}, \mathrm{Li}_{2} \mathrm{CuCl}_{4}$, THF, $-78{ }^{\circ} \mathrm{C}$, ultrasound. 


\section{Results and Discussion}

Citronellol (3), an easily obtainable starting material [9], was tosylated to give the tosylate 4, which subsequently was coupled with either $n$-butylmagnesium bromide or $n$-pentylmagnesium bromide to give the alkenes $\mathbf{5 a}$ and $\mathbf{5 b}$, respectively. Upon oxidation, $\mathbf{5 a}$ and $\mathbf{5 b}$ gave the aldehydes $\mathbf{6 a}$ and $\mathbf{6 b}$, respectively, which in turn were reduced into the corresponding alcohols $\mathbf{7 a}$ and $\mathbf{7 b}$ by $\mathrm{NaBH}_{4}$. Repeated tosylations and cross coupling reactions converted the alcohols $\mathbf{7 a}$ and $\mathbf{7 b}$ into the hydrocarbons $\mathbf{1}$ and $\mathbf{2}$ via the tosylates $\mathbf{8 a}$ and $\mathbf{8 b}$ (Scheme 1).

The preparation of the alkyl tosylates $\mathbf{4 ,} \mathbf{8 a}$ and $\mathbf{8 b}$ were carried out following a Varma-like procedure [10]. According to Kabalka et al. [10], alkyl tosylates can be prepared from alcohols and p-toluenesulfonyl chloride, in the presence of pyridine, by stirring the reactants together in chloroform solution for 2.5-9.0 hours at $0{ }^{\circ} \mathrm{C}$. In our procedure, the reactions were supported by ultrasound irradiation from an ultrasonic processor (steps $\mathrm{i}$ and $\mathrm{v}$ ). The results of a series of experiments are shown in Tables 1 and 2.

Table 1: Preparation of the tosylate 4 under ultrasound irradiation.

\begin{tabular}{cccc}
\hline Entry & $\begin{array}{c}3: \text { TsCl : pyridine } \\
\text { (molar ratios) }\end{array}$ & Time (minutes) & Yield of 4 (\%) \\
\hline 1 & $1: 1: 1$ & 30 & 82 \\
2 & $1: 1: 1$ & 60 & 83 \\
3 & $1: 1: 2$ & 30 & 86 \\
4 & $1: 1: 2$ & 60 & 84 \\
5 & $1: 1.5: 1$ & 60 & 80 \\
6 & $1: 1.5: 2$ & 30 & 91 \\
7 & $1: 1.5: 2$ & 20 & 84 \\
8 & $1: 1.5: 2$ & 40 & 92 \\
9 & $1: 1.5: 3$ & 30 & 92 \\
10 & $1: 2: 2$ & 20 & 86 \\
11 & $1: 2: 2$ & 30 & 92 \\
\hline
\end{tabular}

Table 2: Preparation of the tosylates $\mathbf{8 a}$ and $\mathbf{8 b}$ under ultrasound irradiation.

\begin{tabular}{cccc}
\hline Entry & Tosylate & Time (minutes) & Yield (\%) $^{\mathbf{a}}$ \\
\hline 1 & $\mathbf{8 a}$ & 30 & 74 \\
2 & $\mathbf{8 a}$ & 45 & 92 \\
3 & $\mathbf{8 a}$ & 60 & 93 \\
4 & $\mathbf{8 b}$ & 30 & 78 \\
5 & $\mathbf{8 b}$ & 45 & 91 \\
6 & $\mathbf{8 b}$ & 60 & 91 \\
\hline
\end{tabular}

${ }^{\mathrm{a}} \mathbf{7 a}, \mathbf{7 b}: \mathrm{TsCl}:$ pyridine $=1.0: 1.5: 2.0$ (molar ratio). 
p-Toluenesulfonyl chloride was added to the reaction solutions within a few minutes, i.e. not over an extended period, as described by Kabalka's group [10], and with the assistance of ultrasound irradiation, the reactions occurred quickly (within 30-45 minutes) to give the tosylates in good yields (Tables 1 and 2).

In 1974 Fouquet and Schlosser [11] reported the formation of a C-C single bonds by a cross coupling reaction of alkyl tosylates with pertinent Grignard reagents in the presence of lithium tetrachlorocuprate at $-78{ }^{\circ} \mathrm{C}$ after overnight stirring. Adopting the reaction conditions of Fouquet and Schlosser, but using ultrasound to promote the reactivity, we were able to perform the cross coupling reactions between the tosylates and the Grignard reagents (steps ii and vi) within 30-45 minutes, while still obtaining the products in high yields (Table 3).

Table 3: Ultrasound assisted cross coupling reactions between tosylates and Grignard reagents.

\begin{tabular}{cccc}
\hline Entry & Product & Time (minutes) & Yield (\%) $^{\mathbf{a}}$ \\
\hline 1 & $\mathbf{5 a}$ & 20 & 80 \\
2 & $\mathbf{5 a}$ & 30 & 95 \\
3 & $\mathbf{5 a}$ & 45 & 95 \\
4 & $\mathbf{5 b}$ & 30 & 94 \\
5 & $\mathbf{1}$ & 45 & 93 \\
6 & $\mathbf{2}$ & 45 & 91 \\
\hline
\end{tabular}

The aldehydes $\mathbf{6 a}$ and $\mathbf{6 b}$ can be prepared from the alkenes $\mathbf{5 a}$ and $\mathbf{5 b}$ by ozonolysis [12]. In this work, the alkenes $\mathbf{5 a}$ and $\mathbf{5 b}$ were oxidized by perphthalic acid, then periodic acid [13], to give $\mathbf{6 a}$ and $\mathbf{6 b}$, in of $81-82 \%$ yields, respectively, The alcohols $7 \mathbf{a}$ and $7 \mathbf{b}$ were easily prepared from the aldehydes $\mathbf{6 a}$ and $\mathbf{6 b}$ in yields of $96-97 \%$ by reduction of the latter with sodium borohydride in methanol for 15 minutes.

\section{Conclusions}

5,9-Dimethylpentadecane was prepared from citronellol in the excellent overall yield of 58\% through six steps. By the same procedure, 5,9-dimethylhexadecane was prepared in the overall yield of $56 \%$. The use of ultrasound irradiation combined with the use of optimized repetitive synthetic steps (Scheme 1) offer a convenient method for the synthesis of a variety of related branched hydrocarbons. It should be noticed that also the alkyl groups of the Grignard reagent in steps (ii) and (vi) can be varied.

\section{Acknowledgement}

We thank DANIDA for financial support via the ENRECA programme. 


\section{Experimental}

\section{General}

${ }^{1} \mathrm{H}$ - and ${ }^{13} \mathrm{C}$-NMR spectra were recorded in $\mathrm{CDCl}_{3}$ with TMS as internal reference standard at frequencies $300 \mathrm{MHz}$ and $75 \mathrm{MHz}$, respectively, on a Varian Mercury 300 NMR spectrometer, or alternatively, at frequencies $600 \mathrm{MHz}$ and $150 \mathrm{MHz}$, respectively, on a Varian Inova $600 \mathrm{NMR}$ spectrometer. GC-MS analyses were performed on a Hewlett Packard 5890 Series II apparatus with a Hewlett Packard 5791A MS detector (column: RTX-5MS, 30 m, 0.25 mm, $0.25 \mu \mathrm{m}$ ). A Sonics GE130 ultrasonic processor was used both in the tosylation and the cross coupling reactions. All reagents were purchased from Aldrich, while solvents were from Labscan. The chloroform used in the tosylation reactions was filtered through a plug of alumina to remove ethanol (present as stabilizer) [10].

General procedure for the tosylation of alcohols: 3,7-dimethyl-6-octenyl 4-methylbenzenesulfonate (4)

A mixture of citronellol (6.24 g, $40 \mathrm{mmol})$, pyridine (6.32 g, $80 \mathrm{mmol})$, and chloroform (20 mL) was placed in a 3-neck round flask and cooled to $0{ }^{\circ} \mathrm{C}$ in an ice bath. $p$-Toluenesulfonyl chloride (11.4 $\mathrm{g}, 60 \mathrm{mmol}$ ) was added to the mixture within a few minutes under irradiation from an ultrasonic processor. The reaction was finished within 30 minutes. After adding water $(10 \mathrm{~mL})$, the resulting mixture was extracted with diethyl ether $(70 \mathrm{~mL})$. The ethereal layer was washed with $2 \mathrm{M}$ aqueous $\mathrm{HCl}$, aqueous $\mathrm{NaHCO}_{3}$, and brine. The solvent was removed by evaporation at reduced pressure, and the residue was chromatographed on a column $(24 \times 400 \mathrm{~mm}, 60 \mathrm{~g}$ of silica gel, eluent: $2 \%$ diethyl ether in hexane) to give $11.46 \mathrm{~g}(91 \%)$ of the tosylate 4 . MS (m/e): $310\left(\mathrm{M}^{+}\right)$; 227; 185; 173; 155; 138; 123; 91 (100\%); 81; 69; 55; 41; ${ }^{1} \mathrm{H}-\mathrm{NMR}(300 \mathrm{MHz}) \delta: 0.82$ (d, $\left.J=6.3 \mathrm{~Hz}, 3 \mathrm{H}\right), 1.10-1.65$ (m, 5H), 1.57 (s, 3H), 1.67 (d, $J=1.5 \mathrm{~Hz}, 3 \mathrm{H}), 1.82-1.94$ (m, 2H), 2.45 (s, 3H), 4.06-4.07 (m, 2H), 5.00-5.06 (m, 1H), 7.34 (d, $J=8.3 \mathrm{~Hz}, 2 \mathrm{H}), 7.79$ (d, $J=8.3 \mathrm{~Hz}, 2 \mathrm{H}) ;{ }^{13} \mathrm{C}-\mathrm{NMR}$ (75 MHz) $\delta: 17.63,19.05,21.63$, 25.27, 25.70, 28.88, 35.66, 36.71, 69.06, 124.33, 127.89 (2C), 129.82 (2C), 131.48, 133.26, 144.66.

\section{General procedure for the cross coupling reactions: 2,6-dimethyl-2-dodecene (5a)}

n-Butylmagnesium bromide was prepared from 1-bromobutane (12.33 g, $90 \mathrm{mmol}$ ) and magnesium turnings (2.16 g, $90 \mathrm{mmol})$ in dry diethyl ether $(30 \mathrm{~mL})$ during 30 minutes with assistance of an ultrasonic bath (Branson 1210) at room temperature. The slurry formed was added dropwise to a solution of the tosylate $4(9.3 \mathrm{~g}, 30 \mathrm{mmol})$ in THF $(25 \mathrm{~mL})$ at $-78{ }^{\circ} \mathrm{C}$. A solution of $0.1 \mathrm{M} \mathrm{Li}_{2} \mathrm{CuCl}_{4}$ in THF (3.0 mL) was added to the mixture under ultrasonic irradiation. The mixture was kept at $-78{ }^{\circ} \mathrm{C}$ for 10 minutes, after which the temperature was raised slowly to room temperature. The reaction was completed after ultrasound irradiation for a total of 30-45 minutes after the addition of the $\mathrm{Li}_{2} \mathrm{CuCl}_{4}$ solution. The obtained mixture was poured into a saturated aqueous solution of $\mathrm{NH}_{4} \mathrm{Cl}$ containing crushed ice, which was subsequently extracted with diethyl ether (3x50 mL). The combined organic layers were washed with saturated aqueous $\mathrm{NaHCO}_{3}$, with brine, and then dried (anhydrous $\mathrm{Na}_{2} \mathrm{SO}_{4}$ ). After removal of the solvent by evaporation at reduced pressure, the crude product was purified by column chromatography (24 x $400 \mathrm{~mm}, 30 \mathrm{~g}$ of silica gel, eluent: $n$-hexane) to give $5.58 \mathrm{~g}$ of $5 \mathbf{a}$ 
(95\%). MS (m/e): 196 (M+14), 126, 111, 98, 83, 69 (100\%), 56, 41; ${ }^{1} \mathrm{H}-\mathrm{NMR}$ (300 MHz) 8: 0.84-0.88 (m, 6H), 1.06-1.16 (m, 2H), 1.22-1.44 (m, 11H), 1.60 (s, 3H), 1.68 (d, J = 1.2 Hz, 3H), 1.93-1.99 (m, 2H), 5.08-5.13 (m, 1H); ${ }^{13} \mathrm{C}-\mathrm{NMR}(75 \mathrm{MHz}) \delta:$ 14.34, 17.83, 19.84, 22.94, 25.83, 25.93, 27.24, 29.93, 32.20, 32.66, 37.23, 37.40, 125.36, 131.13.

2,6-Dimethyl-2-tridecene (5b): By the same procedure as described for the cross coupling reaction above, n-pentylmagnesium bromide, prepared from 1-bromopentane (9.06 g, $20 \mathrm{mmol}$ ) and magnesium turnings $(1.44 \mathrm{~g}, 60 \mathrm{mmol})$ in $30 \mathrm{~mL}$ of dry diethyl ether, was reacted with the tosylate 4 (6.20 g, $20 \mathrm{mmol})$ to yield $3.95 \mathrm{~g}(94 \%)$ of $5 \mathbf{b} . \mathrm{MS}(\mathrm{m} / \mathrm{e}): 210\left(\mathrm{M}^{+}, 36\right), 182,140,125,111,98,83,69$

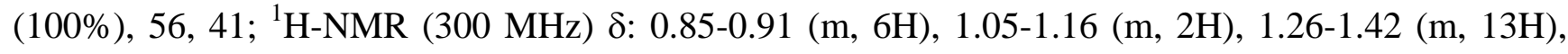
1.60 (s, 3H), 1.68 (d, $J=1.2 \mathrm{~Hz}, 3 \mathrm{H}), 1.88-2.04$ (m, 2H), 5.04-5.14 (m, 1H); ${ }^{13} \mathrm{C}-\mathrm{NMR}(75 \mathrm{MHz}) \delta$ : 14.14, 17.63, 19.64, 22.73, 25.63, 25.74, 27.09, 29.44, 32.03, 31.98, 32.47, 37.03, 37.19, 125.15, 130.92.

General procedure for oxidation: 4-methyldecanal (6a)

A $0.6 \mathrm{M}$ solution of perphthalic acid (70 $\mathrm{mL}, 42 \mathrm{mmol})$ in diethyl ether was added dropwise to a solution of 5a (5.5 g, $28 \mathrm{mmol})$ in dry diethyl ether $(10 \mathrm{~mL})$ at $0{ }^{\circ} \mathrm{C}$, after which the mixture was placed in a refrigerator overnight. The reaction mixture was washed with aqueous $\mathrm{NaHCO}_{3}$, and dried (anhydrous $\mathrm{Na}_{2} \mathrm{SO}_{4}$ ). Then the solvent was removed by evaporation at reduced pressure to leave crude intermediate 2,6-dimethyl-2-dodecene epoxide, which was dissolved in diethyl ether (20 mL) and added dropwise to a stirred solution of $\mathrm{HIO}_{4}(6.84 \mathrm{~g}, 30 \mathrm{mmol})$ in THF (30 mL) during 1.5 hours. Removal of the solvents at reduced pressure gave crude $\mathbf{6 a}$, which was purified by column chromatography (24 x $400 \mathrm{~mm}, 30 \mathrm{~g}$ of silica gel, eluent: 5\% diethyl ether in hexane), to yield $3.85 \mathrm{~g}$ (81\%) of pure 6a as a light yellow oil. MS (m/e): 155, 142, 126, 111, 95, 85, 69, 56 (100\%), 41; ${ }^{1} \mathrm{H}-$

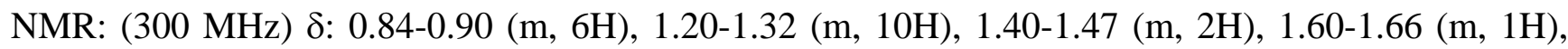
2.39-2.46 (m, 2H), 9.77 (t, $J=1.8 \mathrm{~Hz}, 1 \mathrm{H}) ;{ }^{13} \mathrm{C}-\mathrm{NMR}$ (75 MHz) $\delta: 14.30,19.56,22.87,27.11,29.11$, 29.77, 32.09, 32.59, 36.89, 41.93, 203.30.

4-Methylundecanal (6b): In the same manner as described above for the preparation of $\mathbf{6 a}$, we obtained $2.80 \mathrm{~g}$ (82\%) of $\mathbf{6 b}$ from $3.90 \mathrm{~g}$ of the alkene $5 \mathbf{b}$. MS (m/e): 169, 156, 140, 125, 112, 95, 85,

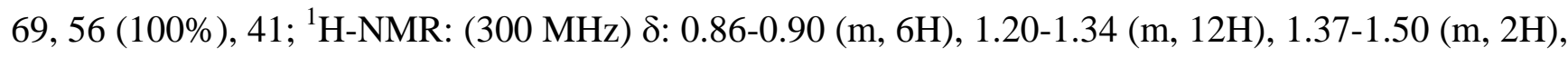
1.60-1.70 (m, 1H), 2.39-2.46 (m, 2H), 9.77 (t, $J=1.8 \mathrm{~Hz}, 1 \mathrm{H}) ;{ }^{13} \mathrm{C}-\mathrm{NMR}(75 \mathrm{MHz}) \delta: 14.31,19.57$, 22.89, 27.16, 29.11, 29.55, 30.08, 32.10, 32.60, 36.90, 41.93, 203.28.

\section{General procedure for reduction: 4-methyl-1-decanol (7a)}

A solution of sodium borohydride $(0.26 \mathrm{~g}, 6.8 \mathrm{mmol})$ in methanol $(7 \mathrm{~mL})$ was added dropwise to $3.80 \mathrm{~g}$ ( $22 \mathrm{mmol}$ ) of $\mathbf{6 a}$ under stirring during 15 minutes at room temperature. The reaction mixture was quenched with $1.0 \mathrm{M}$ aqueous $\mathrm{HCl}(4 \mathrm{~mL})$, and the resulting mixture was extracted with diethyl ether ( 3 x $15 \mathrm{~mL}$ ). The combined organic layers were washed successively with aqueous $\mathrm{NaHCO}_{3}$ and brine, and then dried (anhydrous $\mathrm{Na}_{2} \mathrm{SO}_{4}$ ). After removal of the solvent by evaporation at low pressure, 
the residue was purified by column chromatography $(24$ x $400 \mathrm{~mm}, 30 \mathrm{~g}$ of silica gel, eluent: 10\% diethyl ether in hexane) to give $3.69 \mathrm{~g}(96 \%)$ of 7a. MS (m/e): 126, 111, 98, 84, 69 (100\%), 56, 41; ${ }^{1} \mathrm{H}-$

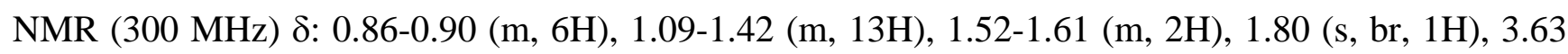
$(\mathrm{t}, J=6.6 \mathrm{~Hz}, 2 \mathrm{H}) ;{ }^{13} \mathrm{C}-\mathrm{NMR}(75 \mathrm{MHz}) \delta: 14.19,19.72,22.82,27.15,29.81,30.40,32.08,32.79$, 33.15, 37.16, 63.20 .

4-Methyl-1-undecanol (7b): In the same manner as described above for the preparation of 7a, we obtained $2.74 \mathrm{~g}$ (97\%) of $\mathbf{7 b}$ from $2.80 \mathrm{~g}$ of the aldehyde $\mathbf{6 b}$. MS (m/e): 140, 125, 112, 97, 84, 69 (100\%), 56, 41; ${ }^{1} \mathrm{H}-\mathrm{NMR}$ (300 MHz) $\delta: 0.86-0.90$ (m, 6H), 1.11-1.40 (m, 15H), 1.52-1.63 (m, 2H), 1.78 (s, br, $1 \mathrm{H}$ ), 3.62 (t, $J=6.6 \mathrm{~Hz}, 2 \mathrm{H}) ;{ }^{13} \mathrm{C}-\mathrm{NMR}$ (75 MHz) $\delta: 14.12,19.65,22.71,27.07,29.40$, 29.99, 30.36, 31.94, 32.65, 32.97, 37.01, 63.45 .

4-Methyl-1-decanyl 4-methylbenzenesulfonate (8a) and 4-methyl-1-undecanyl 4-methylbenzenesulfonate (8b): The tosylates $\mathbf{8 a}$ and $\mathbf{8 b}$ were prepared following the general procedure described above for the preparation of the tosylate 4 . We obtained $6.29 \mathrm{~g}$ (92\%) of $\mathbf{8 a}$ from $3.61 \mathrm{~g}$ of 7a. Data of 8a: MS (m/e): 207 (10), 173 (74), 154 (39), 126 (49), 111 (34), 97 (36), 91 (100), 84 (46), 69 (91), 56 (65), 41 (61); ${ }^{1} \mathrm{H}-\mathrm{NMR}:(300 \mathrm{MHz}) \delta: 0.80$ (d, $\left.J=6.6 \mathrm{~Hz}, 3 \mathrm{H}\right), 0.86-0.90$ (m, 3H), 1.01-1.35 (m, 13H), 1.56-1.72 (m, 2H), 2.45 (s, 3H), 4.01 (t, $J=6.6 \mathrm{~Hz}, 2 \mathrm{H}), 7.36$ (d, $J=8.4 \mathrm{~Hz}, 2 \mathrm{H}), 7.79$ (d, $J=8.4 \mathrm{~Hz}$, 2H); ${ }^{13} \mathrm{C}-\mathrm{NMR}:(75 \mathrm{MHz}) \delta$ : 14.12, 19.41, 21.63, 22.68, 26.48, 26.90, 29.60, 31.91, 32.28, 32.49, 36.78, 71.12, 127.90 (2C), 129.80 (2C), 133.33, 144.62. Analogously, $4.49 \mathrm{~g}$ (91\%) of $8 \mathbf{b}$ was obtained from 2.70 g of $\mathbf{7 b}$. Data of $\mathbf{8 b}$ : MS (m/e): 207 (3), 173 (100), 155, 140, 125, 111, 91, 83, 69, 56, 43, 41; ${ }^{1} \mathrm{H}-\mathrm{NMR}:(300 \mathrm{MHz}) \delta: 0.80$ (d, $\left.J=6.3 \mathrm{~Hz}, 3 \mathrm{H}\right), 0.88$ (t, $J=6.6 \mathrm{~Hz}, 3 \mathrm{H}$ ), 1.07-1.32 (m, 15H), 1.56-1.72 (m, 2H), 2.45 (s, 3H), 4.01 (t, $J=6.6 \mathrm{~Hz}, 2 \mathrm{H}), 7.34$ (d, $J=8.3 \mathrm{~Hz}, 2 \mathrm{H}), 7.79$ (d, $J=$ $8.3 \mathrm{~Hz}, 2 \mathrm{H}$ ); ${ }^{13} \mathrm{C}-\mathrm{NMR}$ : (75 MHz) $\delta:$ 14.06, 19.35, 21.58, 22.69, 26.48, 26.95, 29.35, 29.90, 31.91, 32.27, 32.49, 36.77, 71.11, 127.88 (2C), 129.79 (2C), 133.31, 144.60.

5,9-Dimethylpentadecane (1): 2-Hexylmagnesium bromide was prepared by reaction of $4.80 \mathrm{~g}$ (29 mmol) of 2-bromohexane [14] with magnesium turnings (0.77 g, $32 \mathrm{mmol})$ in dried diethyl ether (30 $\mathrm{mL}$ ) for 2 hours. In the same manner as described for the preparation of the alkene 5a (see general procedure above), we obtained $\mathbf{1}$, albeit together with a very small amount of 5,6-dimethyldecane. After removal of 5,6-dimethyldecane by vacuum distillation (65-68 $\left.{ }^{\circ} \mathrm{C} / 6 \mathrm{mbar}\right), 2.15 \mathrm{~g}$ (93\%) of pure 1 could be isolated (from $3.10 \mathrm{~g}$ (9.5 mmol) of (8a). MS (m/e): $240\left(\mathrm{M}^{+}, 5\right), 225$ (4), 211 (2), 197 (1), 183 (21), 155 (32), 127 (10), 112 (35), 99 (22), 85 (77), 71 (93), 57 (100), 43 (58); ${ }^{1} \mathrm{H}-\mathrm{NMR}$ : (600 MHz) $\delta: 0.84(\mathrm{t}, J=6.6 \mathrm{~Hz}, 3 \mathrm{H}), 0.84(\mathrm{t}, J=6.6 \mathrm{~Hz}, 3 \mathrm{H})$ [15], 0.87-0.90 (m, 6H), 1.02-1.11 (m, 4H), 1.16-1.32 (m, 18H), 1.33-1.39 (m, 2H); ${ }^{13} \mathrm{C}-\mathrm{NMR}:(150 \mathrm{MHz}) \delta: 14.14,14.19,19.72,19.78,22.73$, 23.09, 24.50, 27.09 (27.10) [16], 29.38 (29.40) [16], 29.74, 32.01, 32.77 (32.79) [16], 32.80 (32.82) [16], 36.79 (36.89) [16], 37.12 (37.21) [16], 37.43, 37.48.

5,9-Dimethylhexadecane (2): In the same manner as described above for the preparation of $\mathbf{1}, 1.43$ g (91\%) of 2 was obtained from 2.10 g (6.5 mmol) of $\mathbf{8 b}$. MS (m/e): 254 (M+ 5), 239 (5), 211 (2), 197 (31), 169 (10), 155 (35), 126 (37), 99 (22), 85 (97), 71 (90), 57 (100), 43 (76); ${ }^{1} \mathrm{H}-\mathrm{NMR}$ (300 MHz) $\delta:$ 0.84 (d, J = 6.6 Hz, 6H), 0.87-0.91 (m, 6H), 1.02-1.11 (m, 4H), 1.16-1.39 (m, 22H); ${ }^{13} \mathrm{C}-\mathrm{NMR}:(75$ 


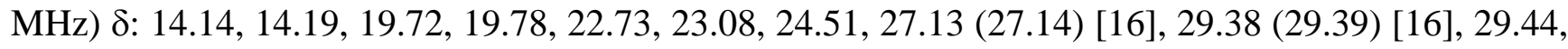
30.03, 31.98, 32.77 (32.79) [16], 32.80 (32.82) [16], 36.79 (36.89) [16], 37.11 (37.20) [16], 37.42, 37.48 .

\section{References and Notes}

1. (a) Mori, K. Synthesis of optically active pheromones. Tetrahedron 1989, 45, 3233-3298; (b) Maier, C. T.; Gries, R.; Gries, G. Sex pheromone components of pitch pine looper, Lambdina pellucidaria. J. Chem. Ecol. 1998, 24, 491-500; (c) Kimura, T.; Carlson, D. A.; Mori, K. Synthesis of all the stereoisomers of 13,17-dimethyl-1-tritriacontene and 13,17-dimethyl-1-pentatriacontene, the contact sex pheromone components of the female tsetse fly, Glossina austeni. Eur. J. Org. Chem. 2001, 3385-3390.

2. Francke, W.; Toth, M.; Szocs, G.; Krieg, W.; Ernst, H.; Buschmann, E. Identification and synthesis of dimethylalkanes as sex attractants of female leaf miner moths (Lyonetiidae). Z . Naturforsch. 1988, 43C, 787-789.

3. Moreira, J. A.; Correa, A. G. Enantioselective synthesis of three stereoisomers of 5,9dimethylpentadecane, sex pheromone component of Leucoptera coffeella, from (-)-isopulegol. Tetrahedron: Asym. 2003, 14, 3787-3795.

4. Kuwahara, S.; Liang, T.; Leal, W. S.; Ishikawa, J.; Kodama, O. Synthesis of All Four Possible Stereoisomers of 5,9-Dimethyldecane, the Major Sex Pheromones Component of the Coffee Leaf Minor Moth, Perileucoptera coffeella. Biosci. Biotechnol. Biochem. 2000, 64, 2723-2726.

5. Zarbin, P. H. G.; Princival, J. L.; Lima, E. R.; Santos, A. A.; Ambrogio, B. G.; Oliveira, A. R. M. Unsymmetrical double Wittig olefination on the syntheses of insect pheromones. Part 1: Synthesis of 5,9-dimethylpentadecane, the sexual pheromone of Leucoptera coffeella. Tetrahedron Lett. 2004, 45, 239-241.

6. Liang, T.; Kuwahara, S.; Hasegawa, M.; Kodama, O. Simple Synthesis of 5,9-Dimethylated LongChain Alkanes, the Sex Pheromones of Leaf Minor Moths. Biosci. Biotechnol. Biochem. 2000, 64, 2474-2477.

7. Poppe, L.; Novák, L.; Dévényi, J.; Szántay, Cs. Baker's yeast mediated synthesis of (5SR,9S)-5,9dimethylheptadecane and (5SR,9S)-5,9-dimethylpentadecane; the main sex-pheromone components of Leocoptera scitella and Perileucoptera coffeella enriched in 9S-isomers. Terahedron Lett. 1991, 32, 2643-2646.

8. Luche, J. L. Synthetic Organic Sonochemistry; Plenum Press: NewYork, 1998.

9. Bauer, K.; Garbe, D.; Surburg, H. Common Fragrance and Flavor Materials, $2^{\text {nd }}$ ed.; VCH: Weinheim, 1990.

10. Kabalka, G. W.; Varma, M.; Varma, R. S.; Srivastava, P. C.; Knapp, F. F., Jr. Tosylation of alcohols. J. Org. Chem. 1986, 51, 2386-2388.

11. Fouquet, C.; Schlosser, M. Improved carbon-carbon linking by controlled copper catalysis. Angew. Chem. Int. Ed. Engl. 1974, 13, 83-85.

12. Zarbin, P. H. G.; Cruz, W. O.; Ferreira, J. T. B. Stereospecific synthesis of two isomers of $(4,8)$ dimethyldecanal: the aggregation pheromone of Tribolium spp. J. Braz. Chem. Soc. 1998, 9, 511-513. 
13. Furniss, B. S.; Tatchell, A. R.; Hannaford, A. J.; Smith, P. W. G. Vogel's Textbook of Practical Organic Chemistry, $5^{\text {th }}$ ed.; Longman: London, 1989; pp. 454-457.

14. Sufficiently pure 2-bromohexane could not be procured commercially, minor contents of the isomeric 3-bromohexane being an apparently unavoidable impurity. Therefore, 2-bromohexane was prepared with the purity of $98 \%$ (GC) from 2-hexanol and $\mathrm{PBr}_{3}$ at a temperature below $5{ }^{\circ} \mathrm{C}$ ([13]; pp. 559-564).

15. The signals are separated from each other by $\Delta \delta=0.002 \mathrm{ppm}$.

16. Resolved resonances for the same carbon atom of two diastereomerically different forms.

Sample Availability: Available from the authors.

(C) 2007 by MDPI (http://www.mdpi.org). Reproduction is permitted for noncommercial purposes. 